\title{
fMRI Evidence for Cortical Modification during Learning of Mandarin Lexical Tone
}

\author{
Yue Wang*,1, Joan A. Sereno ${ }^{2}$, Allard Jongman ${ }^{2}$, and Joy Hirsch ${ }^{3}$
}

\begin{abstract}
Functional magnetic resonance imaging was employed before and after six native English speakers completed lexical tone training as part of a program to learn Mandarin as a second language. Language-related areas including Broca's area, Wernicke's area, auditory cortex, and supplementary motor regions were active in all subjects before and after training and did not vary in average location. Across all subjects, improvements in performance were associated with an increase in the spatial extent of activation in left superior temporal gyrus (Brodmann's
\end{abstract}

\section{INTRODUCTION}

One of the central questions in cognitive neuroscience is how a second language is acquired. According to the critical period hypothesis, puberty is accompanied by a loss of neurological plasticity of the brain, resulting in a reduction in language learning ability (Lenneberg, 1967). Nonetheless, investigations of cortical plasticity and the acquisition of perceptual and motor skills in adulthood (Recanzone, 2000; Karni et al., 1995; Karni \& Sagi, 1993) suggest that cortical representations may be continuously shaped throughout life (Van Turennout, Ellmore, \& Martin, 2000). This notion is also consistent with findings that language-related cortical responses differ as a function of linguistic experience (Gaillard et al., 2000; Perani et al., 1998; Kim, Relkin, Lee, \& Hirsch, 1997; Yetkin, Yetkin, Haughton, \& Cox, 1996). However, the corresponding modifications in the neurobiological systems that underlie the acquisition of a second language have not been determined (Binder, 1999).

Functional magnetic resonance imaging (fMRI) was employed to investigate the cortical effects of learning Mandarin as a second language by adult native speakers of American English. Specifically, in this study, we asked if the neural changes associated with learning Mandarin lexical tones occurred within known language-related areas and/or within new regions recruited for these functions. Secondly, we asked if learning-related neural

\footnotetext{
${ }^{1}$ Cornell University, ${ }^{2}$ University of Kansas, ${ }^{3}$ Memorial SloanKettering Cancer Center, Columbia University

* Presently at Simon Fraser University.
}

area 22, putative Wernicke's area), the emergence of activity in adjacent Brodmann's area 42, and the emergence of activity in right inferior frontal gyrus (Brodmann's area 44), a homologue of putative Broca's area. These findings demonstrate a form of enrichment plasticity in which the early cortical effects of learning a tone-based second language involve both expansion of preexisting language-related areas and recruitment of additional cortical regions specialized for functions similar to the new language functions. changes were represented by centroid shifts or variations in volumes of activated cortical regions.

Tone contrasts in Mandarin Chinese with lexical significance were taught to native speakers of American English by a focused training program, and functional brain images were acquired before and after completion of the course. Mandarin has four distinct lexical tones that differ primarily in pitch height and contour shape. For native speakers, the neural substrate underlying the ability to identify lexical tone is predominantly lateralized in the left hemisphere (Wang, Jongman, \& Sereno, 2001; Van Lancker \& Fromkin, 1973), whereas other nonlexical pitch-related perceptual abilities are predominantly lateralized in the right hemisphere (Goodglass \& Calderon, 1977; Blumstein \& Cooper, 1974). The left hemisphere specialization for lexical tone is not characteristic of adult nonnative Mandarin speakers (Hsieh, Gandour, Wong, \& Hutchins, 2001; Klein, Zatorre, Milner, \& Zhao, 2001; Wang et al., 2001; Gandour et al., 2000). Although native and nonnative speakers process lexical tone differently, nonnative learners' ability to identify linguistic contrasts can be significantly improved after a short perceptual training program (Wang, Spence, Jongman, \& Sereno, 1999; Logan, Lively, \& Pisoni, 1991; Jamieson \& Morosan, 1986). For example, American learners of Mandarin showed a 21\% increase in correct tone identification after approximately 5 hours of structured perceptual training within a 2 -week period. Moreover, this improvement generalized to new contexts and was retained when tested 6 months after training (Wang et al., 1999). In this study, the 
same structured training paradigm was employed to observe the cortical substrates that underlie the processes involved when nonnative speakers learn Mandarin lexical tones. Thus, the related neural changes were directly associated with the process of learning to identify lexical tones in the context of Mandarin words.

Six college-age native speakers of American English who were beginning learners of Mandarin participated in the study. The study involved two identical fMRI scans: an initial scan prior to training and a follow-up scan 2 weeks after training. Each scan consisted of baseline and stimulation periods. During the stimulation period, subjects performed a tone identification task in which they were required to identify 40 auditory presentations of Mandarin lexical items. Each word bore a tone that belonged to one of four possible tonal categories. In the same session, subjects also performed related control tasks with visual, auditory, and motor components. These results were separated from the lexical tone identification images and thus served to increase the specificity of the tone-training results. All brain images for each subject were computationally aligned to allow direct comparisons between pre- and posttraining scans. Anatomical labels, Brodmann's areas, and atlas sectors were assigned to the active regions based on judgments of brain atlas correspondence (Talairach \& Tournoux, 1988).

\section{RESULTS}

In concordance with the previous tone-training study (Wang et al., 1999), the behavioral results in this study demonstrated, on average, a $24 \%$ increase in correct identification of the Mandarin lexical tones, where the pretraining average was $64 \%$ correct and the posttraining average was $88 \%$ correct, $t(5)=-2.6, p<.05$ (Table 1 ). This overall behavioral improvement was the basis for investigating the associated cortical changes. One subject, M.R., reached ceiling performance pretraining (95\% correct) and did not show improvement in tone identification (posttraining: 95\% correct). He was considered separately in the subsequent imaging analyses.

Table 2 lists all cortical regions that were active in both the pretraining and posttraining scans for all five subjects. Tabled values are Brodmann's areas and the right column indicates conserved areas. An area is considered conserved if it is present across all subjects. In the left hemisphere, these areas include the medial frontal gyrus (BA 6, corresponding to supplementary motor cortex), the inferior frontal gyrus (BA 44 and 45, corresponding to Broca's area), the superior temporal gyrus (BA 22, corresponding to Wernicke's area), and the middle temporal gyrus (BA 21, corresponding to secondary auditory cortex). The superior and middle temporal gyri (BA 22 and 21) were also conserved pre- and posttraining within the right hemisphere. Additionally, left BA 42 was conserved in all subjects during the posttraining scan, but not during the pretraining scan. Right BA 44 was also conserved during the post- but not the pretraining scan, although individual analysis showed that three out of five subjects did show activity during pretraining scan in this area.

A comparison of the centroids of the regions activated before and after training indicated that the locations on average did not differ significantly from the pretraining scan to the posttraining scan for those areas conserved for both scans. The average locations (represented in $x, y$, and $z$ coordinates) of the conserved active cortical regions for the pretraining and posttraining conditions are shown in Table 3.

The average number of posttraining activated voxels in the left superior temporal gyrus, BA 22 (1111 \pm 443) exceeded the average number in the pretraining $\operatorname{scan}(797 \pm 409), t(4)=-2.9, p<.044$. No other volume differences were observed (Table 4). This increase of activity within Wernicke's area was not a byproduct of overall variation from pretraining to posttraining because the total number of activated voxels across subjects, for all areas, did not differ for the pretraining scan (average $=12,989 \pm 5,027$ ) and the posttraining scan (average $=12,851 \pm 4,978$ ), suggesting that the increase in active voxel count for BA 22 was a localized effect of tone training.

Figure 1 presents representative images for a typical American trainee (Subject K.D.), illustrating the areas where significant changes were observed before and after training. The figure displays three consecutive axial slices (horizontal sectors: $+8,+12$, and $+16 \mathrm{~mm}$ ), showing the increase in volume of activation in Wernicke's area while performing a Mandarin lexical tone identification task in the pretraining and posttraining scans.

Overall, the present study shows that, across pretest and posttest scans, multiple brain areas were activated bilaterally in both anterior and posterior regions. Comparing the change during before and after training scans, the results reveal an increase in magnitude of posttraining activated cortex in left superior temporal gyrus (BA 22), as well as the emergence of conserved activation in a neighboring region (BA 42) and in the right hemisphere inferior frontal gyrus (BA 44). Taken together, these findings demonstrate both the modification of an existing language-related area and the recruitment of new cortical regions to serve the new lexical tone identification function. These findings are summarized in Figure 2 where areas conserved both pre- and posttraining (red) as well as the posttraining emergence of new regions (yellow) are located on axial slices of the Talairach and Tournoux's (1988) human brain atlas.

Similar tone identification data were acquired from two right-handed male native speakers of Mandarin 
Table 1. Percent Correct Identification of the Mandarin Lexical Tones by the American Learners Before and After Training

\begin{tabular}{lccc}
\hline Subjects & Pretest & Posttest & Improvement \\
\hline R. O. & 15 & 78 & +63 \\
K. D. & 47 & 84 & +37 \\
M. N. & 70 & 88 & +18 \\
M. S. & 75 & 90 & +15 \\
K. R. & 80 & 90 & +10 \\
M. R. & 95 & 95 & 0 \\
Mean & 64 & 88 & +24 \\
\hline
\end{tabular}

Chinese, using the same stimuli as in the pretraining scan for the American learners and the same visual, auditory, and motor control tasks. Figure 3 shows a representative image (horizontal sector: $12 \mathrm{~mm}$ ) for one of the two native Mandarin subjects demonstrating regions of activity when performing the Mandarin tone identification task, with predominant activation in left hemisphere language-related regions.

\section{DISCUSSION}

Learning tone-based distinctions is a fundamental aspect of learning Mandarin as a second language and particularly challenging to native speakers of American English because lexical tone does not have a direct correlate in American English. The four patterns of lexical tone serve a contrastive purpose in Mandarin, that is, they distinguish between words. The acoustic properties of lexical tone are most closely related to patterns of prosody in English (i.e., stress, accent, intonation). This imperfect correspondence of Mandarin lexical tone with any one property of English adds an additional burden to learning Mandarin as a second language. Indeed, current theories posit that language acquisition patterns are influenced by linguistic experience (Kuhl, 2000; Jusczyk, 1997; Best, 1995; Flege, 1995). For example, infants as young as 6-8 months can distinguish a range of phonetic contrasts whether they occur in their native language, but the ability to discriminate nonnative contrasts declines significantly by about 10-12 months (Werker \& Tees, 1984). It has been proposed that this decline in sensitivity to nonnative contrasts is related to the process of assimilating specific instances to prototypes established as a

Table 2. Pretest and Posttest Activation in Anatomical and Brodmann's Areas Per Subject and Hemisphere and Conserved Areas Across Five Subjects

\begin{tabular}{|c|c|c|c|c|c|c|c|}
\hline \multirow[b]{2}{*}{ Area } & \multirow[b]{2}{*}{ Test } & \multicolumn{5}{|c|}{ Subject } & \multirow[b]{2}{*}{ Conserved Areas } \\
\hline & & R. O. & $K . D$. & M. N. & $M . S$. & $K . R$. & \\
\hline \multicolumn{8}{|l|}{$L H$} \\
\hline \multirow[t]{2}{*}{ GFi } & Pretest & $44,45,46$ & $44,45,46$ & $44,45,46$ & 44,45 & $44,45,47$ & 44,45 \\
\hline & Posttest & $44,45,46$ & $44,45,46$ & $44,45,46$ & $44,45,47$ & $44,45,46,47$ & 44,45 \\
\hline \multirow[t]{2}{*}{ GFd } & Pretest & 6 & 6 & 6 & 6 & 6 & 6 \\
\hline & Posttest & 6 & 6 & 6 & 6 & 6 & 6 \\
\hline \multirow[t]{2}{*}{ GTm } & Pretest & $21,22,37$ & 21 & $21,22,39$ & 21,22 & $21,22,39$ & 21 \\
\hline & Posttest & 21 & $21,22,39$ & 21 & 21 & $21,22,39$ & 21 \\
\hline \multirow[t]{2}{*}{ GTs } & Pretest & $22,39,42$ & 22 & 22 & 22 & 22,42 & 22 \\
\hline & Posttest & 22,42 & 22,42 & 22,42 & 22,42 & $22,39,42$ & 22,42 \\
\hline \multicolumn{8}{|l|}{$R H$} \\
\hline \multirow[t]{2}{*}{ GFi } & Pretest & - & $44,45,46$ & $44,45,46$ & 45,47 & $44,45,47$ & - \\
\hline & Posttest & $44,45,46,47$ & $44,45,46$ & $44,45,46$ & 44 & $44,45,47$ & 44 \\
\hline \multirow[t]{2}{*}{ GTm } & Pretest & 21,22 & 21 & $21,22,37$ & 21,22 & $21,22,37,39$ & 21 \\
\hline & Posttest & 21 & 21,39 & 21,37 & 21,22 & $21,22,39$ & 21 \\
\hline \multirow[t]{2}{*}{ GTs } & Pretest & 22,42 & 22 & 22,42 & 22 & $22,39,42$ & 22 \\
\hline & Posttest & 22,42 & 22,42 & 22,42 & 22 & $21,22,39,42$ & 22 \\
\hline
\end{tabular}

$\mathrm{LH}=$ left hemisphere; $\mathrm{RH}=$ right hemisphere; $\mathrm{GFi}=$ inferior frontal gyrus; $\mathrm{GFd}=$ medial frontal gyrus; $\mathrm{GTm}=$ middle temporal gyrus; GTs = superior temporal gyrus. 
Table 3. Pretest and Posttest Activation Centroids (Center of Mass, Talairach and Tournoux Coordinates $[x, y, z]$, in mm) Per Subject and Averaged Across Subjects for Each Conserved Brain Region and Brodmann's Area

\begin{tabular}{|c|c|c|c|c|c|c|c|}
\hline \multirow[b]{2}{*}{ Area } & \multirow[b]{2}{*}{ Test } & \multicolumn{5}{|c|}{ Subject } & \multirow[b]{2}{*}{ Mean } \\
\hline & & R. O. & $K . D$. & $M . N$ & $M . S$. & K. $R$. & \\
\hline \multicolumn{8}{|l|}{$L H$} \\
\hline \multirow[t]{2}{*}{ GFi (44) } & Pretest & {$[35,15,12]$} & {$[52,7,24]$} & {$[51,11,17]$} & {$[52,11,18]$} & {$[52,15,16]$} & {$[48,12,17]$} \\
\hline & Posttest & {$[47,10,12]$} & {$[49,8,22]$} & {$[45,12,18]$} & {$[51,11,19]$} & {$[50,14,17]$} & {$[48,11,19]$} \\
\hline \multirow[t]{2}{*}{ GFi (45) } & Pretest & {$[32,25,8]$} & {$[40,30,12]$} & {$[36,19,14]$} & {$[52,20,12]$} & {$[45,23,11]$} & {$[41,23,11]$} \\
\hline & Posttest & {$[34,25,10]$} & {$[40,27,10]$} & {$[38,17,17]$} & {$[40,25,3]$} & {$[43,23,14]$} & {$[39,23,11]$} \\
\hline \multirow[t]{2}{*}{ GFd (6) } & Pretest & {$[10,-2,58]$} & {$[10,10,45]$} & {$[10,-2,55]$} & {$[5,15,45]$} & {$[5,2,48]$} & {$[8,5,50]$} \\
\hline & Posttest & {$[13,-8,58]$} & {$[8,-2,50]$} & {$[10,2,52]$} & {$[8,4,45]$} & {$[5,7,48]$} & {$[9,1,51]$} \\
\hline \multirow[t]{2}{*}{ GTm (21) } & Pretest & {$[53,-22,0]$} & {$[47,-34,2]$} & {$[45,-45,8]$} & {$[53,-42,5]$} & {$[60,-40,1]$} & {$[52,-37,3]$} \\
\hline & Posttest & {$[55,-50,5]$} & {$[60,-49,2]$} & {$[54,-31,5]$} & {$[52,-52,5]$} & {$[49,-43,2]$} & {$[54,-45,4]$} \\
\hline \multirow[t]{2}{*}{ GTs (22) } & Pretest & {$[54,-36,12]$} & {$[56,-42,14]$} & {$[58,16,10]$} & {$[56,-28,9]$} & {$[56,-33,13]$} & {$[56,-25,12]$} \\
\hline & Posttest & {$[60,-20,4]$} & {$[56,-36,13]$} & {$[54,-23,9]$} & {$[57,-23,7]$} & {$[54,-31,11]$} & {$[56,-27,9]$} \\
\hline \multicolumn{8}{|l|}{$R H$} \\
\hline \multirow[t]{2}{*}{ GTm (21) } & Pretest & {$[-51,-17,-2]$} & {$[-45,-45,1]$} & {$[-55,-60,4]$} & {$[-53,-40,3]$} & {$[-54,-41,3]$} & {$[-52,-41,2]$} \\
\hline & Posttest & {$[-55,-12,-4]$} & {$[-53,-47,4]$} & {$[-53,-46,4]$} & {$[-55,-44,1]$} & {$[-53,-40,1]$} & {$[-54,-38,1]$} \\
\hline \multirow[t]{2}{*}{ GTs (22) } & Pretest & {$[-53,-30,11]$} & {$[-56,-30,12]$} & {$[-54,-33,12]$} & {$[-56,-42,16]$} & {$[-54,-10,3]$} & {$[-55,-29,11]$} \\
\hline & Posttest & {$[-55,4,0]$} & {$[-50,-47,15]$} & {$[-50,-25,9]$} & {$[-63,-40,8]$} & {$[-55,-2,0]$} & {$[-55,-22,6]$} \\
\hline
\end{tabular}

$\mathrm{LH}=$ left hemisphere; $\mathrm{RH}=$ right hemisphere; $\mathrm{GFi}=$ inferior frontal gyrus; $\mathrm{GFd}=$ medial frontal gyrus; GTm = middle temporal gyrus; GTs = superior temporal gyrus; Brodmann's areas are indicated in parentheses.

result of linguistic experience (Kuhl, Williams, Lacerda, Stevens, \& Lindblom, 1992). Along these lines, adults often experience difficulty in perceiving nonnative phonetic contrasts, presumably because the categories specific for one's native language differ from those of the nonnative language (Kuhl, 2000). Nonetheless, discrimination of nonnative contrasts can be significantly improved by experience (Flege, Takagi, \& Mann, 1995; MacKain, Best, \& Strange, 1981) and/or training (Wang et al., 1999; Logan et al., 1991; Jamieson \& Morosan, 1986; Pisoni, Aslin, Perey, \& Hennessy, 1982).

Patterns of prosody also differ from language to language. Very young (4-day-old) infants are able to distinguish utterances in their native language from utterances in a nonnative language and, in fact, prefer native-language utterances. These preferences remain even after utterances are subjected to a low-pass filter that serves to mask phonetic and phonotactic characteristics of the stimuli (Mehler et al., 1988) suggesting an early sensitivity to native language prosodic information. Likewise, adult speech processing is also shaped by the prosodic properties of the native language. Speakers of different languages may or may not be able to utilize certain prosodic information (e.g., lexical stress) in language processing depending on the functional use of that information in their native language (e.g., be it lexically contrastive or not) (Klein et al., 2001; Dupoux, Pallier, Sebastian-Galles, \& Mehler, 1997).

In the initial stages of developing a processing schema related to a specific language, the second-language learner usually has a variety of existing processing strategies and networks related to the native language that may aid in second-language acquisition. However, in the case of lexical tone, which is not a salient prosodic characteristic of American English, a network specifically equipped to deal with this type of linguistic distinction would not be expected. Thus, the learner must develop novel processes capable of integrating tones and phonetic contrasts. The results presented here support this expectation.

The activations conserved across all subjects during both pretraining and posttraining tasks involved seven cortical areas that involve known language- and auditoryrelated systems (Hirsch, Rodriguez-Moreno, \& Kim, 2001; Cabeza \& Nyberg, 2000; Chee, Tan, \& Thiel, 1999; Illes et al., 1999; Binder et al., 1997; Dehaene et al., 1997; Fiez, Raichle, Balota, Tallal, \& Petersen, 1996; Price et al., 1996; Mazoyer, Tzourio, \& Frak, 1993; 
Table 4. Number of Voxels Activated in the Corresponding Cortical Areas in the Pretest and Posttest

\begin{tabular}{|c|c|c|c|c|c|c|c|}
\hline \multirow[b]{2}{*}{ Area } & \multirow[b]{2}{*}{ Test } & \multicolumn{5}{|c|}{ Subject } & \multirow[b]{2}{*}{ Mean } \\
\hline & & R. O. & $K . D$ & $M . N$ & $M . S$. & $K . R$ & \\
\hline \multicolumn{8}{|l|}{$L H$} \\
\hline \multirow[t]{2}{*}{ GFi (44) } & Pretest & 353 & 1276 & 747 & 557 & 449 & 676 \\
\hline & Posttest & 799 & 1318 & 674 & 343 & 740 & 775 \\
\hline \multirow[t]{2}{*}{ GFi (45) } & Pretest & 112 & 425 & 610 & 217 & 270 & 327 \\
\hline & Posttest & 294 & 319 & 331 & 312 & 399 & 331 \\
\hline \multirow[t]{2}{*}{ GFd (6) } & Pretest & 203 & 111 & 592 & 195 & 551 & 330 \\
\hline & Posttest & 467 & 330 & 579 & 243 & 508 & 425 \\
\hline \multirow[t]{2}{*}{ GTm (21) } & Pretest & 179 & 34 & 682 & 270 & 173 & 268 \\
\hline & Posttest & 122 & 142 & 728 & 373 & 247 & 332 \\
\hline \multirow[t]{2}{*}{ GTs (22) } & Pretest & 192 & 172 & 1173 & 201 & 2246 & 797 \\
\hline & Posttest & 376 & 837 & 1403 & 250 & 2688 & $1111 *$ \\
\hline \multicolumn{8}{|l|}{$R H$} \\
\hline \multirow[t]{2}{*}{ GTm (21) } & Pretest & 47 & 70 & 739 & 492 & 1420 & 554 \\
\hline & Posttest & 58 & 289 & 484 & 357 & 1785 & 595 \\
\hline \multirow[t]{2}{*}{ GTs (22) } & Pretest & 109 & 8 & 2011 & 101 & 303 & 506 \\
\hline & Posttest & 296 & 55 & 3098 & 47 & 265 & 752 \\
\hline
\end{tabular}

$\mathrm{LH}=$ left hemisphere; $\mathrm{RH}=$ right hemisphere; $\mathrm{GFi}=$ inferior frontal gyrus; $\mathrm{GFd}=$ medial frontal gyrus; $\mathrm{GTm}=$ middle temporal gyrus; GTs = superior temporal gyrus; Brodmann's areas are indicated in parentheses.

*Posttest is significantly different from pretest at $p<.05$.

Demonet, Chollet, \& Ramsay, 1992; Wise et al., 1991) including the left inferior frontal gyrus (BA 44 and 45), left medial frontal gyrus (BA 6), left and right superior temporal gyrus (BA 22), and left and right middle temporal gyrus (BA 21). Cortical effects of learning Mandarin lexical tones (as determined by increased volume in existing language areas) were found in the left superior temporal gyrus (BA 22), suggesting that the initial stages of learning these tone-based linguistic distinctions were associated with an expansion of neural processes within existing putative Wernicke's area. Furthermore, the emergence of posttraining activity in the neighboring left BA 42 suggests additional neural recruitment to perform these new functions. As Wernicke's area is known to be involved in the processing of auditorily complex stimuli (Binder et al., 2000; Binder, Rao, \& Hammeke, 1994), the increased volume of activation as well as the involvement of an annexed neighboring area suggests an increased devotion of resources to the processing of complex lexical tones. These observations support the prediction that, as learning occurs, areas previously specialized for native language processing as well as neighboring areas develop specializations for nonnative language functions (Perani et al., 1996,
1998). A second example of functional neural recruitment was observed by the posttraining emergence of conserved activation in the right prefrontal cortex (inferior frontal gyrus, BA 44). Prefrontal cortex in the right hemisphere has been linked to pitch judgment tasks (Zatorre, Evans, Meyer, \& Gjedde, 1992) and the processing of affective prosody (Buchanan et al., 2000), whereas left hemisphere prefrontal cortex has been linked to processing of lexical tone in native speakers of tone languages when the presented tones have linguistic relevance (Gandour et al., 2000). The results presented here are consistent with the hypothesis that during the early stages of learning a tone-based language, native speakers of English acquire a novel function (i.e., identification of Mandarin lexical tones) by enhancing an existing system originally specialized for the processing of nonlexical tone. Thus, we speculate that further neural changes might be expected to occur as the linguistic relevance of the tones increases for these nonnative speakers.

Interestingly, the most proficient learner (M. R.), who already showed high tone identification performance at pretest and no behavioral improvement from pretest to posttest, activated the same regions as those 
Figure 1. A comparison of preand posttraining activity in Wernicke's area. Activity within the left superior temporal gyrus, BA 22, is overlaid on T2* base images. Representative contiguous axial slices, acquired $+8,+12$, and $+16 \mathrm{~mm}$ superior to the AC/PC line (subject K.D.), show an increase in activated volume during the lexical tone identification task after training. Voxels that passed the multistage statistical criteria within the boxed regions at a level of $p \leq .0001$ are yellow, $p \leq .0025$ are orange, and $p \leq .0005$ are red. $\mathrm{R}$ indicates the right side of the brain. Non-modulated areas in the pre- and posttest scans are not shown in this figure.

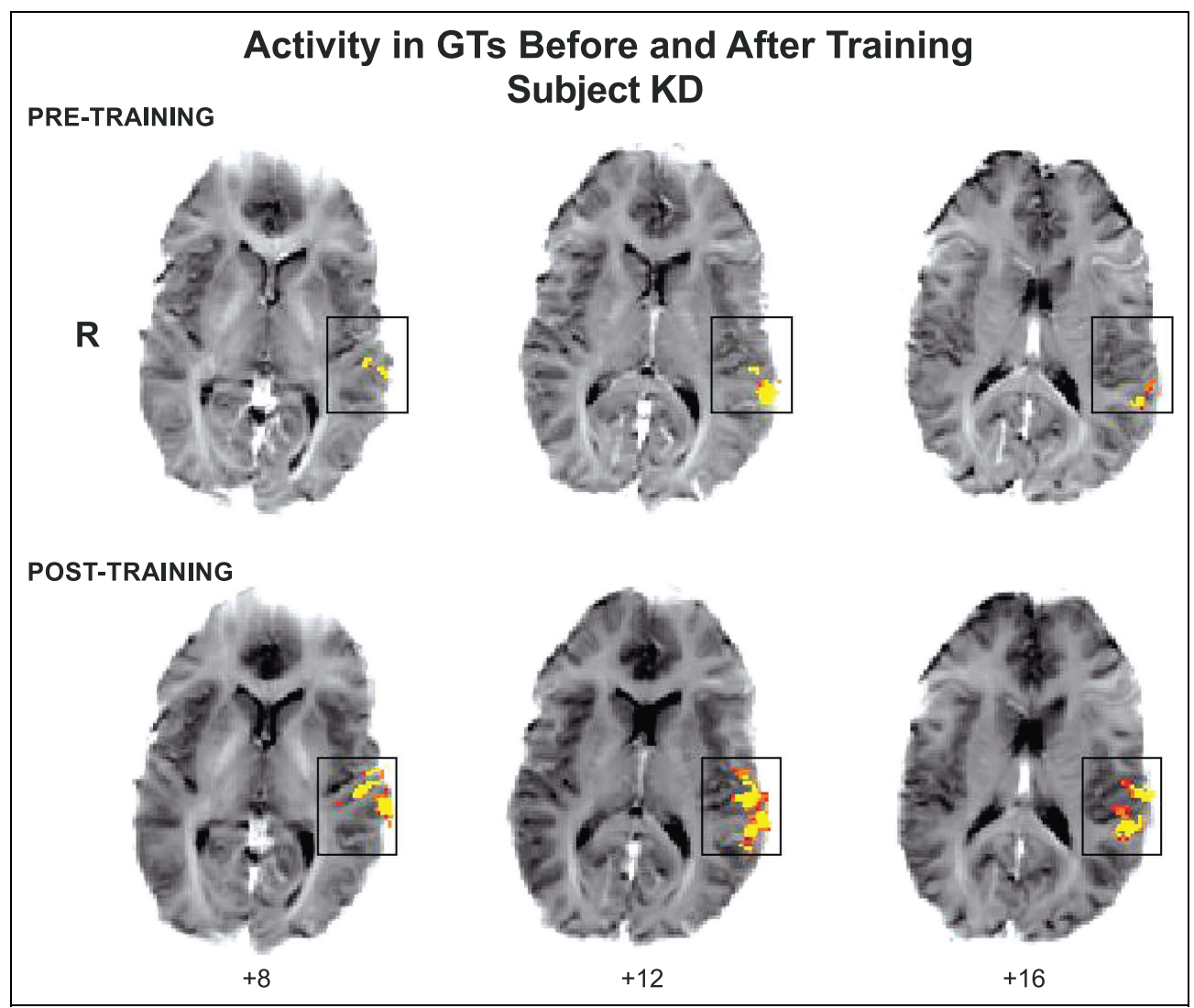

conserved for the other subjects. However, the amount of overall activation in these areas decreased from pretest $(17,789$ voxels) to posttest (6,654 voxels) with a similar drop in the total number of activated voxels within Wernicke's area (from 2,469 to 1,440 voxels). Thus, for this one "advanced" learner, cortical activity related to lexical tone processing became more focused with training. The possibility of such focused change in cortical activation with higher relative language proficiency has also been noted with visually presented words (Chee, Hon, Lee, \& Soon, 2001). The pattern observed in this individual raises the possibility of progressive cortical changes with increased proficiency, and suggests that the results of this study,

\section{REGIONS ACTIVE DURING THE MANDARIN LEXICAL TASK Conserved For All Subjects}
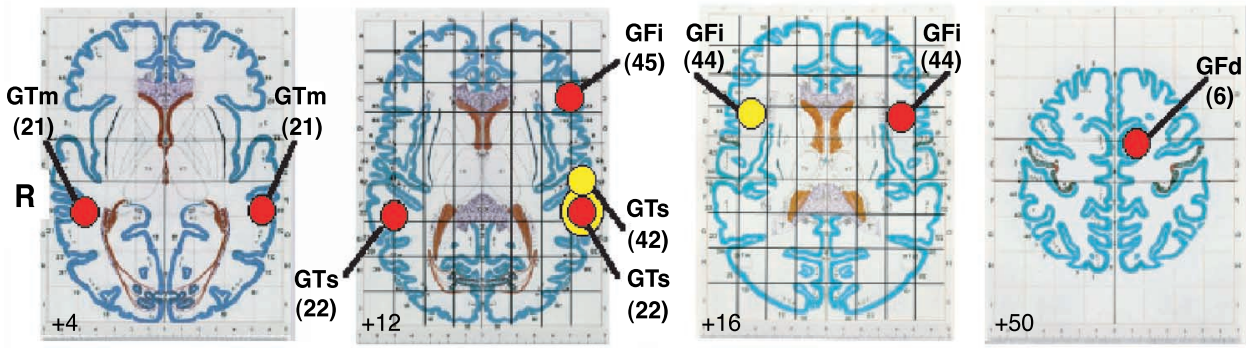

\section{O AFTER TRAINING ONLY \\ BEFORE AND AFTER TRAINING}

Figure 2. Summary of cortical effects before and after training. Red circles represent the average locations of the conserved regions present before and after training: GTm, middle temporal gyrus (BA 21); GTs, superior temporal gyrus (BA 22), left inferior frontal gyrus (BA 45 and 44), and left medial frontal gyrus (BA 6) (Table 2). These areas did not vary with respect to average centroid location before and after training (Table 3). The yellow regions indicate posttraining effects and include the expansion of the active area in left GTs, BA 22 (yellow annulus, Table 4) plus the emergence of activity in neighboring left BA 42 (plate +12 ), and the emergence of activity in right GFi, BA 44 (plate +16$)$. 


\section{Regions Active During the Mandarin Lexical Task Native Mandarin Speaker}

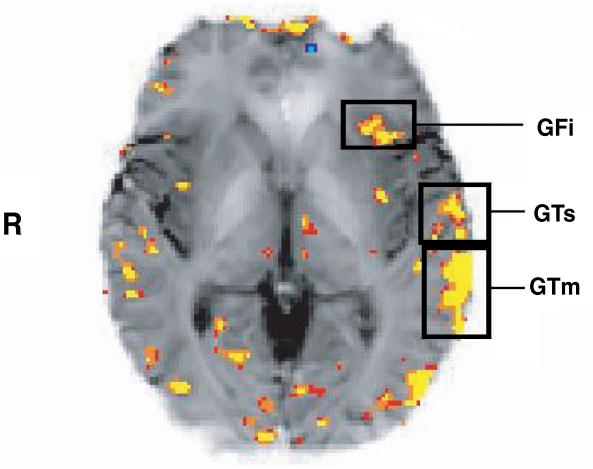

Figure 3. Native Mandarin speaker. A representative axial slice acquired $12 \mathrm{~mm}$ superior to the AC/PC line from a native Mandarin speaker, showing all areas of activation during the Mandarin tone identification task. It demonstrates typical left-side-biased activation in language-sensitive regions, including inferior frontal gyrus (GFi), superior temporal gyrus (GTs), and middle temporal gyrus (GTm).

which occur within 2 weeks of training, represent early cortical changes.

Taken together, we find that the neural changes associated with lexical tone training include (1) an increase in existing working cortical volume within left superior temporal gyrus (BA 22), (2) recruitment of additional working cortical volume within left superior temporal gyrus (BA 42), and (3) recruitment of additional cortical volume within right inferior frontal gyrus (BA 44). These findings suggest a form of enrichment plasticity in which cortical areas are expanded and/or recruited to perform new language functions similar to those of their original specialization.

\section{METHODS}

\section{Image Acquisition}

A 1.5-T General Electric magnetic resonance scanner was used to obtain T2*-weighted images with a gradient-echo pulse sequence that was sensitive to magnetic resonance signal changes induced by alteration in the proportion of deoxyhemoglobin in the local vasculature accompanying neuronal activation (Ogawa, Lee, Nayak, \& Glynn, 1990). The in-plane resolution was $1.5 \times 1.5 \mathrm{~mm}$ and slice thickness was $4.5 \mathrm{~mm}$. Twenty-one contiguous axial slices of the brain, which covered the entire cortex, were taken parallel to the anterior-posterior commissure line. Thirty-six images were acquired for each run: a baseline (resting) period of 10 images (40 sec), a stimulation period of 10 images $(40 \mathrm{sec}$ ), and a baseline (recovery) period of 10 images $(40 \mathrm{sec})$. The first and last three images were not included in the analysis. For details, see Hirsch et al. (2001) and Kim et al. (1997).

\section{Subjects}

Six native speakers of American English (4 women and 2 men) without speech and hearing impairments participated in the study. All were university students who had taken Mandarin Chinese courses for one semester and had no experience with a tone language prior to learning Mandarin. Participants were right-handed, as assessed by the Edinburgh Handedness Inventory (Oldfield, 1971), and recruited according to institutional informed consent procedures. All were paid for their participation.

\section{Experimental Design}

During the first pair of runs, subjects tapped their righthand fingers and thumb while viewing a flashing checkerboard that was back-projected onto a screen located at the foot of the scanner platform. Subjects viewed the checkerboard through a slanted mirror incorporated into the head coil and located above the head. During the second pair of runs, subjects listened to pure auditory tone sweeps through headphones that were designed to reduce background scanner noise. During the last pair of runs, subjects performed the Mandarin lexical tone identification task. Twenty Mandarin words (each with one of the four tones) were presented in each run, with an interstimulus interval of 2 sec. Subjects identified which tone was heard by indicating with za laser pointer secured to the right hand the corresponding tone mark located on the viewing screen. An experimenter recorded subject responses and calculated accuracy scores.

The training consisted of eight sessions of 40 minutes each, during which subjects were trained auditorily to identify the four tones. The training stimuli included 180 monosyllabic Mandarin real words produced by four native speakers of Mandarin. See Wang et al. (1999) for details of the training procedure.

\section{Functional Magnetic Resonance Imaging Data Analysis}

Activation of each voxel was determined by a multistage statistical analysis that compared mean amplitude of signals acquired during stimulation and baseline periods. This technique also required statistically significant signal changes on two identical runs (Kim et al., 1997) resulting in an empirically determined false positive rate of $p \leq .0001$ for each condition. To eliminate the nonspecific visual, motor, and auditory information in the tone identification runs, a "logical exclusion," AND NOT operation, was employed to segregate activity associated with the finger-tapping (motor), checkerboard (vision), and the tone sweep (auditory) functions from the lexical tone identification tasks, presumably yielding activity unique to Mandarin 
lexical tone identification. Comparison of pre- and posttraining images was based on aligned data sets. Two logical operations were performed on the thresholded images: pre- AND posttraining presumably reflecting regions activated for all conditions (Hirsch et al., 2001) and posttraining, NOT pretraining, presumably reflecting activity unique to the postlearning state.

Assignments of anatomical labels were made by two independent investigators based on correspondence between the anatomy and the human brain atlas (Talairach \& Tournoux, 1988). Conventional high-resolution (T1-weighted) images were also acquired along the same plane locations as the T2*-weighted images and served as anatomical references. The stages of assignment included the (1) identification of the brain slice passing through the AC/PC line and location of respective commissures on the axial view, (2) assignment of an atlas plate to each acquired brain slice, (3) identification of the location of the vertical AC/PC plane on all brain slices, (4) identification of the location of the central sulcus on all $\mathrm{T} 2 *$-weighted slices where it was represented and confirmation of those landmarks on all T1*-weighted images, and (5) assignment of the corresponding anatomical labels, Brodmann's areas, and atlas sectors for each active cluster. The corresponding set of 21 high-resolution T1 images acquired on the same plane lines was employed to clarify all anatomical landmarks on the $\mathrm{T} 2 *$-weighted images, and, in particular, all representations of the central sulcus. This process was achieved in the same manner for all subjects and yielded a summary tabulation containing anatomical regions, Brodmann's area, and the transformed atlas sectors for each of the clusters of activated voxels. These data were converted from descriptions of individual brains to generalized findings by determination of the anatomical and Brodmann's areas conserved across all subjects. An area is considered conserved if it is present for all subjects in the experiment (Hirsch et al., 2001). The "epicenter" of activity was calculated as the 3-D center-of-mass for each cluster based on atlas coordinates and then averaged across all subjects (Kim et al., 1997).

The T2*-weighted images were displayed on the original acquisition grid indicating the actual metric of the brain with an in-plane resolution of 1.5 by $1.5 \mathrm{~mm}$. Each brain region conserved across all subjects was defined for each individual brains by these grid boundaries and all voxel counts reflect activity within these areas defined by the anatomy alone. Since pre- and posttraining scans for each subject were aligned, these areas were identical for both conditions.

\section{Acknowledgments}

The authors thank the Memorial Sloan-Kettering Cancer Center (Cancer Center Support Grant C1-P30-CA-08748) and the University of Kansas for research funds. Joel Pardee, Associate Dean, Weill Graduate School of Medical Sciences at Cornell University, provided essential support to bridge the programs between the Ithaca and the New York City Cornell University campuses that enabled this project. Melissa Sy and Sarah Callahan assisted with data analysis and manuscript development, respectively.

Reprint requests should be sent to Yue Wang, Linguistics Department, Simon Fraser University, 9201 Robert Brown Building Burnaby, BC, V5A 156 Canada, or via e-mail: yw36@ hotmail.com.

The data reported in this experiment have been deposited with The fMRI Data Center archieve (http://www.fmridc.org). The accession number is 2-2003-113MW.

\section{REFERENCES}

Best, C. T. (1995). A direct realist view of cross-language speech perception. In W. Strange (Ed.), Speech perception and linguistic experience (pp. 171-204). Baltimore: York Press.

Binder, J. R. (1999). Functional MRI of the language system. In C. T. W. Mooner \& P. A. Bandettini (Eds.), Functional MRI (pp. 407-419). Berlin: Springer-Verlag.

Binder J. R., Frost J. A., Hammeke T. A., Bellgowan P. S., Springer J. A.Kaufman J. N., \& Possing E. T. (2000). Human temporal lobe activation by speech and nonspeech sounds. Cerebral Cortex, 10, 512-528.

Binder, J. R., Frost, J. A., Hammeke, T. A., Cox, R. W., Rao, S. M., \& Prieto, T. (1997). Human brain language areas identified by functional MRI. Journal of Neuroscience, 17, 353-362.

Binder, J. R., Rao, S. M., \& Hammeke, T. A., (1994). Functional magnetic resonance imaging of human auditory cortex. Annuals of Neurology, 35, 662-672.

Blumstein, S., \& Cooper, W. (1974). Hemispheric processing of intonation contours. Cortex, 10, 146-158.

Buchanan, T., Lutz, K., Mirzazade, S., Specht, K., Shah, N., Zilles, K., \& Jäncke, L. (2000). Recognition of emotional prosody and verbal components of spoken language: An fMRI study. Cognitive Brain Research, 9, 227-238.

Cabeza, R., \& Nyberg, L. (2000). Imaging cognition II: An empirical review of 275 PET and fMRI studies. Journal of Cognitive Neuroscience, 12, 1-47.

Chee, M. W. L., Hon, N., Lee, H. L., \& Soon, C. S. (2001). Relative language proficiency modulates BOLD signal change when bilinguals perform semantic judgments. Neuroimage, 13, 1155-1163.

Chee, M. W. L., Tan, E. W. L., \& Thiel, T. (1999). Mandarin and English single word processing studied with functional magnetic resonance imaging. Journal of Neuroscience, 19, 3050-3056.

Dehaene, S., Dupoux, E., Mehler, J., Cohen, I., Paulesu, E., Perani, D., van de Moortele, P. F., Lehericy, S., \& Le Bihan, D. (1997). Anatomical variability in the cortical representation of first and second language. NeuroReport, 8, 3809-3815.

Demonet, J. F., Chollet, F., \& Ramsay, S. (1992). The anatomy of phonological and semantic processing in normal subjects. Brain, 115, 1753-1768.

Dupoux, E., Pallier, C., Sebastian-Galles, N., \& Mehler, J. (1997). A distressing "deafness" in French? Journal of Memory and Language, 36, 406-421.

Fiez, J. A., Raichle, M. E., Balota, D. A., Tallal, P., \& Petersen, S. E. (1996). PET activation of posterior temporal regions during auditory word presentation and verb generation. Cerebral Cortex, 6, 1-10. 
Flege, J. E. (1995). Second language speech learning theory, findings, and problems. In W. Strange (Ed.), Speech perception and linguistic experience (pp. 233-273). Baltimore: York Press.

Flege, J. E., Takagi, N., \& Mann, V. (1995). Japanese adults can learn to produce English /r/ and // accurately. Language and Speech, 38, 25-55.

Gaillard, W. D., Hertz-Pannier, L., Mott, S. H., Barnett, A. S., LeBihan, D., \& Theodore, W. H. (2000). Functional anatomy of cognitive development: fMRI of verbal fluency in children and adults. Neurology, 184, 180-185.

Gandour, J., Wong, D., Hsieh, L., Weinzapfel, B., Van Lancker, D., \& Hutchins, G. D. (2000). A crosslinguistic PET study of tone perception. Journal of Cognitive Neuroscience, 12, 207-222.

Goodglass, H., \& Calderon, M. (1977). Parallel processing of verbal and musical stimuli in right and left hemispheres. Neuropsychologia, 15, 397-411.

Hirsch, L., Rodriguez-Moreno, D., \& Kim, K. H. S. (2001). Interconnected large-scale systems for three fundamental cognitive tasks revealed by functional MRI. Journal of Cognitive Neuroscience, 13, 289-405.

Hsieh, L. Gandour, J., Wong, D., \& Hutchins, G. D. (2001). Functional heterogeneity of inferior frontal gyrus is shaped by linguistic experience. Brain and Language, 76, $227-252$

Illes, J., Francis, W. S., Desmond, J. E., Gabrieli, J. D. E., Glover, G. H., Poldrack, R., Lee, C. J., \& Wagner, A. D. (1999). Convergent cortical representation of semantic processing in bilinguals. Brain and Language, 70, 347-363.

Jamieson, D. G., \& Morosan, D. E. (1986). Training non-native speech contrasts in adults: Acquisition of the English contrast by Franco-phones. Perception and Psychophysics, 40, 205-215.

Jusczyk, P. W. (1997). The discovery of spoken language. Cambridge: MIT Press.

Karni, A., Meyer, G., Jezzard, P., Adams, M. M., Turner, R., \& Ungerleider, L. G. (1995). Functional MRI evidence for adult motor cortex plasticity during motor skill learning. Nature, 377, 155-158.

Karni, A., \& Sagi, D. (1993). The time course of learning a visual skill. Nature, 365, 250-252.

Kim, K. H. S., Relkin, N. R., Lee, K. M., \& Hirsch, J. (1997). Distinct cortical areas associated with native and second languages. Nature, 388, 171-174.

Klein, D., Zatorre, R. J., Milner, B., \& Zhao, V. (2001). A cross-linguistic PET study of tone perception in Mandarin Chinese and English speakers. Neuroimage, 13, 646-653.

Kuhl, P. K. (2000). A new view of language acquisition. Proceedings of the National Academy of Sciences, U.S.A., 97, 11850-11857.

Kuhl, P. K., Williams, K. A., Lacerda, F., Stevens, K. N., \& Lindblom, B. (1992). Linguistic experience alters phonetic perception in infants by six months of age. Science, 255, 606-608.

Lenneberg, E. (1967). Biological foundations of language. New York: Wiley.

Logan, J. S., Lively, S. E., \& Pisoni, D. B. (1991). Training Japanese listeners to identify English $/ \mathrm{r} /$ and $/ /$ : A first report. Journal of the Acoustical Society of America, 89, 874-886.

MacKain, K. S., Best, C. T., \& Strange, W. (1981). Categorical perception of English / $\mathrm{r} /$ and $/ \mathrm{l} /$ by Japanese bilinguals. Applied Psycholinguistics, 2, 369-390.

Mazoyer, B. M., Tzourio, N., \& Frak, V. (1993). The cortical representation of speech. Journal of Cognitive Neuroscience, 5, 467-479.

Mehler, J., Jusczyk, P., Lambertz, G., Halsted, N., Bertoncini, J., \& Amiel-Tison, C. (1988). A precursor of language acquisition in young infants. Cognition, 29, 143-178.

Ogawa, S., Lee, T. M., Nayak, A. S., \& Glynn, P. (1990).

Oxygenation-sensitive contrast in magnetic resonance image of rodent brain at high magnetic fields. Magnetic Resonance in Medicine, 14, 68-78.

Oldfield, R. C. (1971). The assessment and analysis of handedness: The Edinburgh Inventory. Neuropsychologia, 9, 97-113.

Perani, D., Dehaene, S., Grassi, F., Cohen, L., Cappa, S. F., Dupoux, E., Fazio, F., \& Mehler, J. (1996). Brain processing of native and foreign languages. NeuroReport, 7, 2439-2444.

Perani, D., Paulesu, E., Sebastian Galles, N., Dupoux, E., Dehaene, S., Bettinardi, V., Cappa, S. F., Fazio, F., \& Mehler, J. (1998). The bilingual brain: Proficiency and age of acquisition of the second language. Brain, 121, 1841-1852.

Pisoni, D. B., Aslin, R. N., Perey, A. M., \& Hennessy, B. L. (1982). Some effects of laboratory training on identification and discrimination of voicing contrasts in stop consonants. Journal of Experimental Psychology: Human Perception and Performance, 8, 297-314.

Price, C. J., Wise, R. J., Warburon, F. A., Moore, C. J., Howard, D., Patterson, K., Frackowiak, R. S., \& Friston, K. J. (1996). Hearing and saying: The functional neuro-anatomy of auditory word processing. Brain, 119, 919-931.

Recanzone, G. H. (2000). Cerebral cortical plasticity: Perception and skill acquisition. In M. S. Gazzaniga (Ed.), The new cognitive neurosciences (pp. 237-247). Cambridge: MIT Press.

Talairach, J., \& Tournoux, P. (1988). Co-planar stereotaxic atlas of the buman brain. New York: Thieme.

Van Lancker, D., \& Fromkin, V. A. (1973). Cerebral dominance for pitch contrasts in tone language speakers and in musically untrained and trained English speakers. Journal of Phonetics, 6, 19-23.

Van Turennout, M., Ellmore, T., \& Martin, A. (2000). Longlasting cortical plasticity in the object naming system. Nature Neuroscience, 3, 1329-1334.

Wang, Y., Jongman, A., \& Sereno, J. A. (2001). Dichotic perception of Mandarin tones by Chinese and American listeners. Brain and Language, 78, 332-348.

Wang, Y., Spence, M. M., Jongman, A., \& Sereno, J. A. (1999). Training American listeners to perceive Mandarin tones. Journal of the Acoustical Society of America, 106, 3649-3658.

Werker, J. F., \& Tees, R. C. (1984). Cross-language speech perception: Evidence for perceptual reorganization during the first year of life. Infant Behavior and Development, 7, 49-63.

Wise, R., Chollet, Hadar, U., Friston, K., Hoffner, E., \& Frackowiak, R. (1991). Distribution of cortical neural networks involved in word comprehension and word retrieval. Brain, 114, 1803-1817.

Yetkin, O., Yetkin, F. Z., Haughton, V. M., \& Cox, R. W. (1996). Use of functional MR to map language in multilingual volunteers. American Journal of Neuroradiology, 17, 473-477.

Zatorre, R., Evans, A., Meyer, E., \& Gjedde, A. (1992). Lateralization of phonetic and pitch processing in speech perception. Science, 256, 846-849. 